\title{
Listing Standards and Fraud
}

\section{MANAGERIAL AND DECISION ECONOMICS, FORTHCOMING (2013)}

\author{
Douglas Cumming \\ Professor and Ontario Research Chair \\ York University - Schulich School of Business \\ 4700 Keele Street \\ Toronto, Ontario M3J 1P3 \\ Canada \\ http://ssrn.com/author $=75390$ \\ douglas.cumming@gmail.com
}

\author{
Sofia Johan \\ Extramural Fellow \\ Tilburg Law and Economics Centre (TILEC) \\ University of Tilburg \\ and \\ York University - Schulich School of Business \\ 4700 Keele Street \\ Toronto, Ontario M3J 1P3 \\ Canada \\ http://ssrn.com/author=370203 \\ sjohan@schulich.yorku.ca
}

March 27, 2012

* The CFA Institute financed this report, and Robert Dannhauser and James Allen at CFA Institute provided helpful support, comments and inspiration. Ashish Aurora, Tarka Chiba, Bentley Cross, Brahm Klar, Ashish Naik and Yujin Ye provided valuable research assistance with data collection. For helpful comments and suggestions we also owe thanks to Daniel Sokol, Gordon Smith and the seminar participants at the CFA-FAJ-Schulich Conference on Financing Public and Private Firms: Fraud, Ethics and Regulation (Toronto, April 2012), the Eastern Finance Association (Boston, April 2012), the Association Française de Science Economique (Paris, July 2012), the Academy of Entrepreneurial Finance (New York, September 2012), the Canadian Law and Economics Association (Toronto, September 2012), the Financial Management Association (Atlanta, October 2002), and the Law and Entrepreneurship Retreat (Washington D.C., 2013). 


\title{
Listing Standards and Fraud
}

\begin{abstract}
Statistics reporting litigated cases of fraud on an exchange-by-exchange basis are not readily available to investors. This paper introduces data from three countries with multiple exchanges operating under different listing standards, - Canada, the United Kingdom and the United States - to show litigated cases of fraud significantly vary by country, and the different exchanges within the country. Comparisons are also made to Brazil, China and Germany to assess out-of-sample inferences. The data examined suggest there are significant differences in the nature of observed fraud across exchanges within the United States; by contrast, outside the United States there appears to be a comparative lack of enforcement. The data also suggest policy implications for the ways in which fraud should ideally be reported to improve investor knowledge, market transparency and market quality.
\end{abstract}

Keywords: Corporate fraud; Exchange listing standards, Securities commissions, NYSE, NASDAQ, TSX, TSXV, LSE, AIM, PinkSheets

JEL classification: G32; J33 


\section{Introduction}

Reports of fraud, particularly among individuals, funds and companies that act on behalf of other people, attract significant media attention and public outrage. Fraud within financial markets erodes investors trust, and in turn influences stock market liquidity and performance (Karpoff et al., 2008a; Srinivasan, 2005). Expected fraud is a risk that should be priced in a wellfunctioning market (Farber, 2005; Karpoff et al., 2008a,b). Yet, are investors really aware of how common fraud actually is, and how different types of fraud differ across exchanges and across countries?

This paper examines reported cases of fraud on exchanges in Canada (Toronto Stock Exchange (“TSX”) and Toronto Stock Exchange - Ventures (“TSXV”)), the United Kingdom (London Stock Exchange (“LSE”) and the Alternative Investment Market (“AIM”)), and the United States (New York Stock Exchange (“NYSE”), National Association of Securities Dealers Automated Quotations (“NASDAQ”), and the OTC Markets Group, informally known as the "PinkSheets"). We group fraud into eight different types, based on an analysis of observed litigated cases. We present new data that were assembled by recording information found within court documents, regulator announcements, and news reports from these three countries. The data highlight differences in frequency of litigated cases of fraud depending on the country and exchanges over the period January 2005 to June 2011. The evidence addresses the question as to whether there is a need for regulators to account for different levels of litigated fraud on different exchanges, and to make this information available to the average investor that seeks to understand risks associated with investing in different products. 
The frequency of fraud cases can be explained by differences in listing standards on an exchange and in turn the composition of companies listed on the exchange, as well as differences in surveillance and enforcement. Despite the widespread fascination with fraud and its welldocumented influence on stock prices, liquidity and market quality, there is little or no direct source of evidence on actual litigated cases of fraud that enable an investor to compare different jurisdictions, or even different exchanges within the same jurisdiction. Note some examples:

- In the United States (“U.S.”), there is no summary document made available to investors that enable investors to compare fraud cases on NYSE versus NASDAQ, or to draw comparison with the PinkSheets. ${ }^{1}$ We show fraud litigation cases per year involving NYSE companies on average represent $1.9 \%$ of NYSE listings, but $4.5 \%$ of NASDAQ listings and over 5\% of PinkSheet listings.

- A review of fraud cases in Canada, the United Kingdon (“U.K.”) and the U.S. shows eight major types of cases: financial fraud, non-financial misrepresentation and disclosure fraud, illegal distributions, bribery, pump-and-dump, wash / matched / improper trade / marketing the close, insider trading, and delinquent in filings with the Commission. In the U.S., all types of fraud are consistently more common on NASDAQ than NYSE (with the sole exception of bribery, where there is a trivially higher frequency of bribery among NASDAQ than NYSE companies). PinkSheet company fraud, by contrast, is dominated by illegal distribution cases and cases involving delinquent filings with the Commission.

\footnotetext{
${ }^{1}$ In this report unless otherwise explicitly stated we refer to all classes of OTC and PinkSheet companies as the 'PinkSheets' following the conventional use of the term.
} 
- Investors should care about fraud. For example, for financial misconduct, firms lose $41 \%$ of their market value on average (Karpoff et al. 2008b). Financial fraud comprises 7.79\% of NASDAQ listings and $2.01 \%$ of NYSE companies. This implies an expected cost of $3.2 \%$ of the value of a NASDAQ listing and $0.8 \%$ of the value of a NYSE listing. Given the absence of reporting of differences in fraud across exchanges, it is unclear whether or not investors take this into account for their investment and/or pricing decisions.

- In Canada, there is no ready document that enables an investor to make comparisons of litigated fraud between the senior TSX versus the TSXV. Likewise, in the U.K. there is no readily available basis to compare litigated fraud on the senior LSE with the junior AIM. We show fraud cases involving TSX companies represent on average $0.3 \%$ of TSX listings and $0.1 \%$ of TSXV listings. Fraud cases involving LSE companies represent 0.4\% of LSE listings and $0.1 \%$ of AIM listings. These differences are best explained by the comparative problems with enforcement with Canada's fragmented securities commissions.

- An increase in minimum capitalization requirements by 1-standard deviation is associated with a reduction in the total number of initiated fraud cases by $27.4 \%$, and a reduction in the total number of sanctioned cases by $45.8 \%$ relative to the average number of cases in each exchange-year in the data. 
- While there is no central source of data to compare other markets, hand gathering information reveals some interesting facts from other exchanges. For instance, Brazil only just completed its first insider trading case in 2011. The defunct Neur Markt had merely 4 confirmed cases of fraud and 25 documented rumors of suspected fraud in its brief history. By contrast, there are plenty of litigated cases of fraud in China, representing $3.8 \%$ of listed companies per year, and it is noteworthy that there are no material differences in listing standards between the Shanghai and Shenzen stock exchanges and, likewise, no material differences in fraud across these two exchanges.

We stress the fact that litigated cases of fraud are not necessarily representative of actual cases of fraud. The difference between actual cases and litigated cases depend on rule setting (listing standards and exchange trading rules), surveillance (the people and technology available to detect fraud), and the quality of enforcement (the process and expenditures to enable cases to go forward and the effectiveness of courts). Our comparisons in this paper between Canada, the U.K. and the U.S. involve three jurisdictions that have similar exchange trading rules, surveillance technology, similar court structures, similar expenditures on enforcement per capita, and all follow common law traditions.

Overall, the data highlight some key findings. Within the U.S., there are pronounced differences in listing standards and higher listing standards are associated with fewer cases of fraud. Pursuit of fraud by the SEC is arguably vigorous relative to other jurisdictions. The very low level of detected fraud in Canada and the U.K. is perhaps best attributable to lower levels of enforcement in Canada and the U.K., or at least a different approach to enforcement without the 
use of formal proceedings. Also, we consider the possibility that the low level of detected fraud on AIM may be a result of a positive role for Nominated Advisers "NOMADs" in mitigating fraud, but we do not find significant evidence in support of this idea in the data. NOMADs are essentially the underwriters for AIM listings that are charged with the continuous supervision of such listings, a unique requirement of AIM.

This paper is organized as follows. The next section describes different types of fraud and differences in the regulatory environment in Canada, the U.K. and the U.S. The third section introduces the data. The fourth section provides multivariate tests. The fifth section discusses additional robustness tests, extensions and future research. The sixth section discusses additional insights from other jurisdictions such as China, Brazil and Germany. The seventh section provides a discussion of policy implications. The final section provides policy implications and concludes.

\section{Fraud, Governance and Listing Standards}

In this section we review in the first subsection different types of fraud and provide examples of fraud in relation to listing standards from actual cases. Thereafter we explain the extent to which differences in listing standards and other regulatory factors exist among the seven markets in Canada (TSX and TSXV), the U.K. (LSE and AIM) and the U.S. (NYSE, NASDAQ and PinkSheets). Finally, in the last subsection we develop testable hypotheses based on the related literature on differences between junior and senior exchanges in terms of the risks and returns to investors, and the interplay between fraud and financial markets. 


\subsection{Types of Fraud and Motivating Examples}

Securities fraud may be broadly grouped into different categories, and it is useful to do so for the purpose of understanding the nature of illegal activities carried out in different marketplaces. In this report we group fraud into one of eight different categories.

- Financial Fraud: examples include revenue misstatements and options backdating. For example, in February 2011 the NASDAQ company, ArthroCare Corp., faced charges that it had materially overstated and prematurely recognized revenue to help the company reach aggressive internal revenue targets and satisfy analysts' revenue expectations. Another example includes the NASDAQ company, SafeNet Inc., which faced SEC litigation in December 2009 for backdated options and quarterly earnings management. An example from Canada includes a 2009 case involving Research In Motion Ltd. (RIM), whereby three respondents from RIM agreed to pay $\$ 68,100,000$ as part of one settlement agreement with the Ontario Securities Commission (OSC) for inappropriate stock option granting practices to senior management.

- Other Fraudulent misrepresentation and disclosure: examples include various types of misstatements to the public, including failure to put in place internal checks to avoid such material misrepresentations from happening, but excluding cases directly involving financial fraud given the separate category above. For example, in December 2008 
PinkSheet company, GMC Holding Corp., faced SEC litigation for allegedly defrauding investors by issuing false press releases touting the company's development of a motor technology device capable of generating unlimited energy and its negotiations to sell this technology for hundreds of millions of dollars.

- Illegal distribution: examples typically include companies or brokers offering to sell company stock without a valid registration statement. For instance, prior to its IPO in 2004 and 2005, Google Inc. offered to sell and sold its securities without a registration statement filed or in effect and without a valid exemption from registration.

- Bribery: examples typically involve bribery of government officials. For instance, in September 2008 NYSE-listed Halliburton Co. was involved in SEC litigation for its involvement to bribe Nigerian government officials over a 10-year period, in violation of the Foreign Corrupt Practices Act in order to obtain construction contracts. It paid a disgorgement fee of \$177 million to settle the charges in 2009.

- Insider Trading: involves trading on material non-public information. For example, in March 2011 there was SEC litigation involving NASDAQ company, MTC Technologies, Inc., involving trading prior to MTC's public announcement on Friday, December 21, 2007, that it had entered into a definitive agreement to be acquired by BAE Systems, Inc.

- Pump and dump: also known as a boiler room scheme, this scheme involves purchasing shares at successively higher prices and then subsequently manipulating the market by 
reversing the positions obtained. This scheme may or may not involve contemporaneous false statements. For example, an individual named Daryl O. Anderson conducted a stock scalping scheme which involved Coudtech Sensors Inc., a PinkSheet company, and faced SEC litigation for the illegal practice of recommending that others purchase a security, while secretly selling the same security, contrary to the recommendation. Here, the illegal practice is carried out by an individual but the harm to the company's investors is notable and a sign that companies on certain exchanges are more prone to such abuse.

- Other Types of Market Manipulation: examples of market manipulation apart from pump-and-dump schemes include wash trades (the same client reference is on both sides of the trade), pre-arranged matched trades (the client broker and another broker enter a bid and ask for the same volume and price, which then generates a trade between the two brokers for the whole of the volume, where the volume of the order is significant given the trading history of the security), and marking the close (selling of securities at the close of the market in an effort to alter the closing price of the security). ${ }^{2}$ An example of litigated market manipulation involves the PinkSheet company, High Country Bancorp Inc., which in April 2011 faced SEC litigation for "marking the close” in certain thinlytraded securities by executing trades in the final minutes of the last trading day of the month with the intention of artificially affecting the securities' closing prices.

- Delinquent in its period filings with the Commission: this type of fraud simply involves companies that fail to file required documents to the SEC, Financial Services Authority

\footnotetext{
${ }^{2}$ A complete list of these different types of market manipulation frauds is provided in Cumming and Johan (2008) and Cumming et al. (2011).
} 
(FSA) in the U.K. or the Canadian Securities Administrators (CSA) in Canada. Also, it includes cases such as the December 2009 FSA case involving Simon Kuun, and the April 2010 FSA case involving Getco Europe Limited, both for failing to provide accurate and timely transaction reports to the FSA.

\subsection{Listing Standards and Other Regulatory Differences in Canada, the U.K. and the U.S.}

Listing rules, ongoing disclosure requirements and trading rules at all stock exchanges are readily available from exchange webpages. Listing standards vary significantly across exchanges in the U.S. For example, the NYSE requires pre-tax earnings of US\$10 million over the 3 years prior to the IPO and US\$25 million in each of the 2 years prior to the IPO, and requires a public float of US\$100 million. The NASDAQ Capital Market requires pre-tax earnings of US\$750,000 and a public float of US\$5 million, while the NASDAQ National requires a public float of US\$20 million (but no restriction on pre-tax earnings).

The OTC Markets Group, informally known as the PinkSheets, is not a stock exchange according to the SEC, but does facilitate the exchange of securities between qualified independent brokers. There are no formal listing standards for the PinkSheets and the SEC does not regulate the PinkSheets. ${ }^{3}$ However, companies may nevertheless have to file financial statements with the SEC if they have 500 or more investors and US\$10 million or more in assets, and if they list on the OTC Bulletin Board (OTCBB). Also, there are a number of unstated listing requirements for PinkSheets in terms of the practice for maintaining a listing, ${ }^{4}$ which include

\footnotetext{
${ }^{3}$ See Securities and Exchange Commission (2011).

${ }^{4}$ http://www.venturelawcorp.com/listing_requirements_pink_sheets.htm
} 
having a minimum of 40 stockholders of record holding one board lot each, not being a blank check company, having current financial information available to market makers and stockholders, and having a market maker submit 15c211 application to NASD and agree to act as market maker for securities of company. Further, foreign companies must have applied as exempt issuers under $12 \mathrm{~g} 3-2 \mathrm{~b}$ with the SEC.

There currently are two equity markets in Canada: the TSX, for senior equities and TSXV, the junior Venture exchange. TSXV requires pre-tax earnings of Can $\$ 100,000$ and a public float of Can $\$ 1,000,000 .{ }^{5}$ The TSX requires pre-tax earnings of Can $\$ 300,000$ and a public float of Can $\$ 4,000,000 .{ }^{6}$

The LSE and AIM have two tier markets - Primary Listed and Secondary Listed. Both Primary and Secondary Listed stocks on the LSE are required to have a minimum market capitalization of $£ 700,000$ and a minimum free float of $25 \%$, or $25 \%$ of the total shares outstanding listed on the exchange. AIM has no listing standards in terms of a minimum float and minimum market capitalization. The Primary Listed on AIM are, however, required to have audited historical financial information for 3 years, $75 \%$ of the business supported by revenue earning record for the 3-year period prior to listing, control over the majority of assets for the 3year period, and a Sponsor (bank, stock broker or other professional sponsor); by contrast, the

\footnotetext{
${ }^{5}$ The TSXV actually has a Tier 2 listing standard of $\$ 50,000$ pre-tax earnings and $\$ 500,000$ public float. Listing standards on the TSXV and its predecessors are not materially different.

${ }^{6}$ Note that the senior TSX also has a Technology Company Listing Standard and a Discretionary Listing category, both of which are more lax than the TSX standards. See Harris (2006).
} 
Secondary Listed company on AIM is only required to have audited financial statements for the 3-year period if available or whichever shorter history applies and no other similar requirement. ${ }^{7}$

A unique feature of the AIM market is that it requires its companies to be subject to continuous oversight by its underwriter also known as a Nominated Adviser (“NOMAD”). AIM companies do not have admission documents pre-vetted by AIM itself or the FSA but rather by the NOMAD (virtually all AIM companies avoid the U.K. Listing Authority prospectus requirement, unlike LSE companies). NOMADs are required at all times for AIM companies, otherwise they will be suspended. NOMADs ensure disclosure of all price-sensitive material in a timely manner, as well as semi-annual reports. NOMADs ensure that AIM companies meet suitability requirements through qualitative assessment of the business plan, management team, and readiness to be public which involves things like valuation, accuracy of revenue forecasts and ability to make timely disclosures. NOMADs also test marketing with institutions and confirm director quality. NOMADs essentially act as a "front-line intermediary" between the exchange and the issuer company.

AIM is similar to the TSXV in the sense that it is a junior "venture" exchange, but that is really where the similarity ends. It distinguishes itself in three important ways (Koyanagi, 2008). First, AIM is regulated by London Stock Exchange-AIM Regulation, a division of an exchange with a lighter touch relative to the TSXV which is an exchange and securities commissionregulated market. Second, AIM is a Sarbanes-Oxley free zone, while TSXV is a Sarbanes-Oxley “light” zone. That is, in Canada, liability for violating disclosure obligations has been influenced

\footnotetext{
${ }^{7}$ http://www.londonstockexchange.com/companies-and-advisors/main-market/documents/brochures/admission-anddisclosure-standards.pdf .
} 
by Sarbanes Oxley legislation, albeit with unique defenses and procedural safeguards within the Canadian rules that mitigate liability and the number of lawsuits found in the U.S. (Blakes, Cassels and Graydon LLP, 2010). Third, AIM does not require a prospectus, while TSXV does require a prospectus which is reviewed and approved by securities regulators prior to admission.

The flexibility of junior markets such as TSXV and AIM has attracted significant interest among issuers and investors alike. For example, more money was raised on AIM in 2006 (US\$31 billion) than on NASDAQ (US\$29 billion) (Securities and Exchange Commission, 2010). In 2007, there were 207 IPOs on the TSX (raising Can\$7.3 billion), 366 on the TSXV (Can\$0.5 billion), 284 on AIM (US\$14.2 billion) and 290 on NASDAQ (US\$17.4 billion) (Securities and Exchange Commission, 2011).

Historically speaking, the U.S. exchanges have been steadily losing their share of IPOs and public capital raising since 2001. In May 2011 the SEC approved NASDAQ's new BX Venture Exchange. Listing requirements for the BX Venture Exchange include 200,000 publicly held shares, 200 public shareholders, US\$2 million market value for initial listing and US\$1 million for continued listing, two market-makers, a minimum listing price of US\$1.00 per share and subsequent listing price not below US\$0.25 per share, and if the company has not previously been listed on a national securities exchange then it must have US\$1 million in shareholders' equity or US\$5 million in assets and a 1-year operating history with a plan to have sufficient working capital for another 12 months. This new development will enable much research on market quality in the U.S. in the future as data become available. In the meantime, comparisons 
are possible between NYSE, NASDAQ, TSX, TSXV, LSE, AIM and the PinkSheets, as discussed below.

\subsection{Testable Hypotheses}

Our empirical tests below focus on the proposition that fraud differs across exchanges due to the characteristics of the exchange, and not merely due to market conditions and/or the characteristics of companies listed on the exchange.

The most pronounced differences across the exchanges in Canada, the U.K. and the U.s. are the listing standards. As discussed immediately above, listing standards are highest on the NYSE. Listing standards are somewhat comparable between NASDAQ and LSE, but arguably tighter on the LSE given the extra conditions such as a Sponsor. Listing standards are notably lower on the TSX, and even lower on the TSXV. The AIM market has lower financial listing standards among these recognized exchanges, but does nevertheless have a NOMAD requirement to enhance governance. Finally, the PinkSheets are not formally an exchange and has the lowest requirements.

While there are massive differences in listing rules, there are much less pronounced regulatory and institutional differences between Canada, the U.K. and the U.S. The legal setting and securities regulation are very similar in Canada, the U.K. and the U.S. (La Porta et al., 1997, 1998, 2006). Trading rules relating to market manipulation show slight differences between Canada, the U.K. and the U.S., but not in a way that is material for the purpose of understanding 
differences in fraud (Cumming et al., 2011). There are not pronounced differences in market manipulation surveillance across Canada, the U.K. and the U.S. (Cumming and Johan, 2008). Moreover, the expenditure on securities law enforcement in terms of the regulators' budget per billion U.S. dollar of GDP is very similar in Canada (US\$82,706), the U.K. (US\$80,902) and the U.S. (US\$83,232), and such expenditures are important for litigating fraud and ensuring market quality (Jackson and Roe, 2009, Table 2). Therefore, to the extent that there are differences in fraud across exchanges in Canada, the U.K. and the U.S., these differences are best accounted for in terms of listing standards and not trading rule setting, surveillance and enforcement expenditures, technology and/or legal settings.

The standard Becker (1968) formulation shows that the probability of committing fraud is a function of the expected payoff and expected penalties from fraud. Expected penalties of fraud depend on the magnitude of the penalty and the expected probability of detection. Lower listing standards are associated with less transparent companies and as such lower listing standards and less transparency likewise are expected to be associated with greater challenges for regulators in detecting fraud (Macey and O'Hara, 2002). The lower the listing standards, the lower the market-induced penalties for fraud (the market's reaction to reported cases of fraud); ${ }^{8}$ this is important because market induced penalties are typically more costly than the financial penalties imposed by securities commissions (Karpoff et al., 2008a). Therefore, for a given dollar of expenditure on enforcement, and for a given probability that firms actually commit fraud, we would expect a greater proportion of fraud to be detected on exchanges with higher listing standards. But higher transparency not only means it is easier for regulators to detect fraud and

\footnotetext{
${ }^{8}$ Similarly, Rau (2012) shows market valuation effects from bribing are smaller for bribing firms based outside North America.
} 
prosecute cases, it also means that firms are less likely to commit fraud. With lower listing standards, firms are more likely to be able to shroud their fraudulent activities and thereby have lower expectations of being caught (Jensen, 2011). We expect this latter effect to dominate if firms contemplating fraud take into account the fact that they have a smaller chance of being detected in a less transparent market. As between NASDAQ and NYSE, therefore, lower listing standards on NASDAQ might be expected to be associated with less transparency and therefore a greater incidence of fraud; hence, we expect to more frequently observe cases of litigated fraud for NASDAQ companies relative for NYSE companies. Similarly, we expect fraudulent activities to be observed more often among the PinkSheets than the NASDAQ and NYSE companies.

It is difficult for the SEC to monitor PinkSheet companies, and the SEC acknowledges this and even issues warnings on point. ${ }^{9}$ In this market, the easiest type of fraud to detect often is the failure to file requisite reports that are required by a Commission. ${ }^{10}$ We therefore expect this type of fraud to be most commonly observed among Pinksheet companies.

In Canada, there are separate securities commissions in each provincial jurisdiction carrying out enforcement, which makes it comparatively more difficult to enforce fraud among publicly traded firms in Canada relative to the U.K. and the U.S. Also, the lower Canadian listing standards encourage the presence of marginal firms to raise capital, as well as the presence of marginal promoters of stock to investors. ${ }^{11}$ As well, the more complex and costly registration process in Canada could make violations more likely. To this end, lower listing standards are

\footnotetext{
${ }^{9}$ http://www.sec.gov/answers/pink.htm

${ }^{10}$ As described below, only a subset of Pinksheet companies are required to file.

${ }^{11}$ See Johan (2010) and Carpentier et al. (2012).
} 
expected to be associated with a greater propensity of illegal distributions that violate securities regulation requirements for a prospectus in Canada relative to the U.K. and U.S. In the U.K., raising capital on an exchange requires a Sponsor (for the senior LSE) or a NOMAD (for AIM). The formal requirement for this intermediary can be expected to alleviate the likelihood of illegal distributions and other types of fraud (Mallin, 2006; Mallin and Ow-Yong, 2010), unlike the legal setting in Canada.

Other factors may bear relevance on the frequency of fraud cases in different countries. For instance, Professor John Coffee (Coffee, 2005) argues that corporate governance scandals that swept through the U.S. and not Europe shortly after the Internet bubble burst were attributable to dispersed ownership in the U.S. and the lack of independence of intermediaries such as auditors (see also Erikson et al., 2006, on equity incentives). Another possibility includes the cultural forces that account for international differences in the way people behave, including those aspects of culture that have been studied by Hofstede. ${ }^{12}$ In our empirical tests below, therefore, we consider not merely differences across countries but also differences across exchanges within the same country. While our data do not enable us to completely rule out all possible alternative explanations for observed differences across exchanges, they nevertheless show extremely pronounced patterns with clear policy implications.

\footnotetext{
${ }^{12}$ Hofstede’s cultural indices available at http://www.geert-hofstede.com/
} 


\section{Data and Summary Statistics}

The data used in this study were recorded from three sources: the CSA in Canada, the FSA in the U.K., and the SEC in the U.S. The records of securities cases are maintained in different ways in these jurisdictions. In Canada, there is an annual reporting service for all securities regulation cases. The reports break information down by the type of case, but do not include information on fraud litigation by type of exchange. In the U.K. the FSA publicly releases new announcements about new cases and updates to ongoing cases. These FSA news announcements however do not include information about which exchange is involved and/or breakdowns about the type of case. As well, these news announcements are comingled with other type of news announcements that are completely unrelated to fraud or securities litigation. In the U.S., the SEC keeps an online searchable database on securities litigation cases, but does not provide summary information about the number or types of cases by exchange. ${ }^{13}$

To assemble the data in a way that was comparable across exchanges, we coded pieces of information that were common to each country: the exchange involved, the date in which the case was initiated, whether or not there was some form of sanction as at June 2011, and the type of case. We recorded information starting in January 2005, primarily because Canadian case records prior to that date are not reliably available. Data were collected up to June 2011 for each country, the time at which data were collected. The total number of cases assembled amounted to 4,190 for the three countries over the years considered.

\footnotetext{
${ }^{13}$ A limitation with the dataset (an indeed a limitation with how case information is disclosed in public files) is that it is not always possible to ascertain whether or not litigation involving a non-listed company also involved a listed company. For example, it is possible a non-listed agent illegally distributed both public and private securities, and whether or not public securities are involved (and which exchange) is not always known from case records.
} 
In the data, $73 \%$ of the cases were from the SEC in the U.S., $16 \%$ from the CSA in Canada and 11\% from the FSA in the U.K. Among all cases across the exchanges and all years the following became evident: 6.9\% involved a known NYSE company; $20.7 \%$ involved a known NASDAQ company; 44.8\% involved a known PinkSheet company; 1\% involved a known LSE company; 0.2\% involved an AIM company; 0.8\% involved a TSX company; 0.4\% involved a TSXV company; 1\% involved a company listed on another exchange; ${ }^{14}$ and $25.1 \%$ of the cases involved a private (non-listed) company.

Private companies in the U.S. subsample are captured in the dataset if they carried out a fraud that involved an unknown public (listed) company; that is, the specific public company or companies involved is not known from the case file. Private companies are captured in the U.K. and Canadian data if they carried out a fraud that involved either a public or private company which is likewise of an unknown identity; it was not possible to isolate public from private companies in the unknown U.K. and Canadian data.

Across Canada, the U.K. and the U.S., the year distribution shows $13.0 \%$ of fraud actions were initiated in $2005,9.7 \%$ in $2006,14.8 \%$ in $2007,15.7 \%$ in $2008,16.7 \%$ in $2009,20.8 \%$ in 2010, and $9.3 \%$ in the first half of 2011. This pattern is consistent with the idea that securities commissions are under political pressure to take on more fraud actions in times of weaker market conditions. ${ }^{15}$ Figure 1 shows a similar pattern by year across each jurisdiction.

\footnotetext{
${ }^{14}$ A small number of cross listings are present in the data. These cross listings are immaterial in our empirics.

${ }^{15}$ There are a couple of alternative explanations for these patterns. First, as the economy sours, companies on the edge are more likely to cut corners to try to survive, thus finding themselves in breach of various laws and regulations. Second, these companies may have been engaged in some type of irregularity or illegality all
} 


\section{Figure 1. Yearly Distribution of Cases by Jurisdiction}

This figure presents the percentage of securities fraud cases in the data by jurisdiction: SEC in the U.S., CSA in Canada, and FSA in the U.K. Percentages are reported relative to the total number of cases on each exchange over the entire period comprising cases initiated between January 2005 and June 2011, as summarized in Table 1.

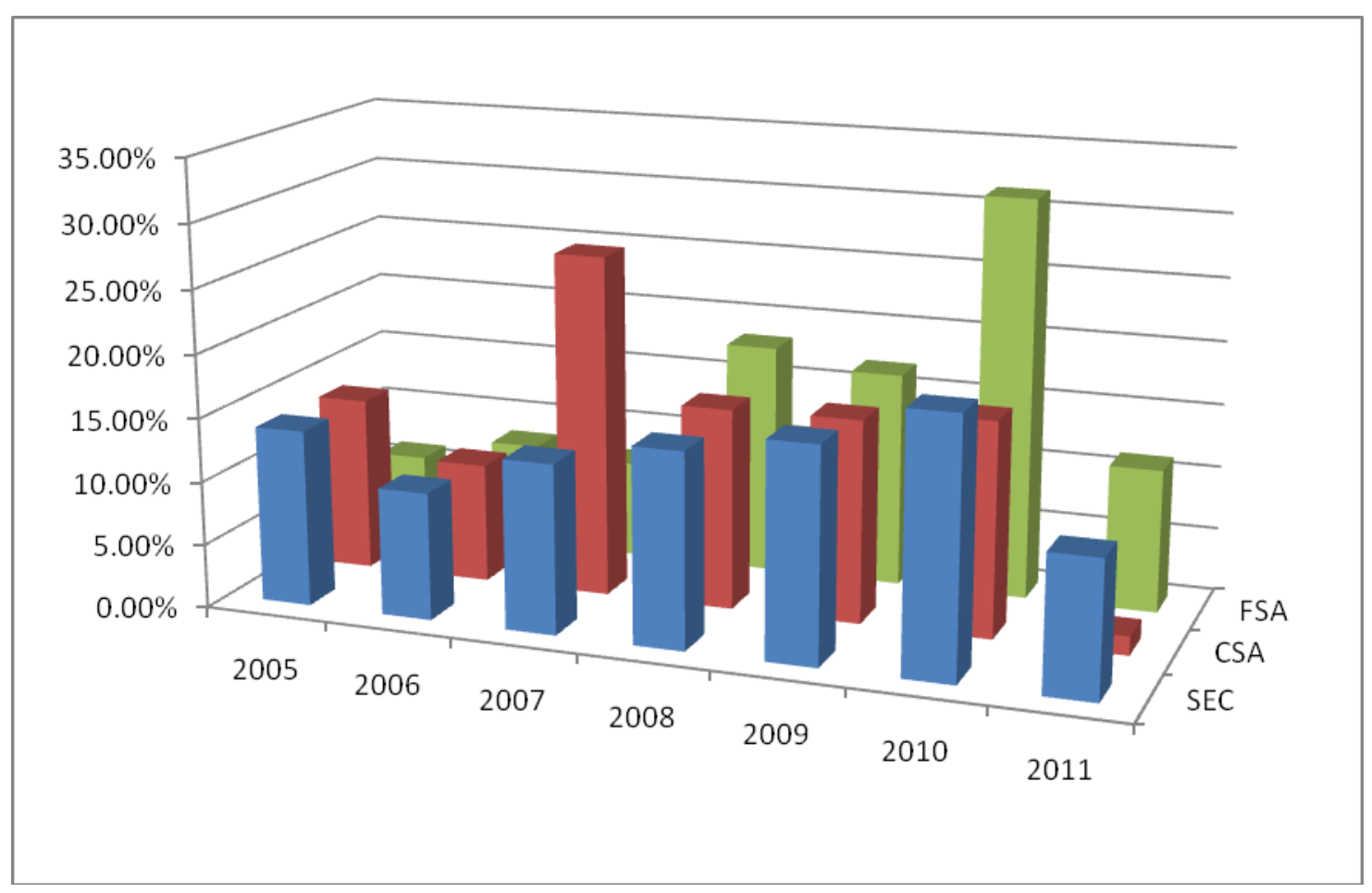

The most common type of violation among the entire period and for all countries is delinquency to file the required materials with the commission (28.5\%), followed by nonfinancial fraudulent misrepresentation and disclosure (18.1\%); illegal distribution (17.6\%); financial fraud (13.8\%); insider trading (11.5\%); pump and dump (5.2\%); other forms of manipulative trading such as wash trades, matched trades, and marking the close (4.7\%); and last but not least, bribery (0.7\%). A majority of cases $(60 \%)$ were resolved with some form of 
sanction (as at June 2011). For ease of comparability, because sanctions differ across jurisdictions depending on severity and type, we simply track whether or not there has been a sanction. This allows us to examine whether or not the subsample of sanctions provides results that are comparable to the full sample in our regression analyses in the next section.

Table 1 breaks down types of violation cases (defined above) by exchange in Panel A and provides comparison tests in Panel B. Table 1 indicates both the number of cases and number of listed companies. All types of fraud litigation cases per year involving NYSE companies on average represent $1.9 \%(=12.12 \% / 6.5$ years $)$ of NYSE listings, but $4.5 \%$ of NASDAQ listings and $5.1 \%$ of the much larger number of PinkSheet listings. By contrast, all types of fraud cases involving TSX companies represent on average $0.3 \%$ of TSX listings and only $0.1 \%$ of TSXV listings. Similarly, all types fraud cases involving LSE companies represent $0.4 \%$ of LSE listings and $0.1 \%$ of AIM listings. A large proportion of litigated frauds in Canada and the U.K. involve private companies; these cases sum to $2.2 \%$ of the total number of listed companies in Canada per year and $2.0 \%$ of the total number of listed companies in the U.K. per year.

Table 1 shows that in the U.S., all types of fraud are consistently more common on NASDAQ than NYSE (with the sole exception of bribery, where there is a trivially higher frequency of bribery among NASDAQ than NYSE companies). In the U.S., financial fraud, insider trading and improper trading is more often litigated (relative to the number of listed companies) on NASDAQ than NYSE and the PinkSheets (which is likely due to the fact that class-action attorneys are more focused on these issues for NASDAQ and NYSE companies than PinkSheet companies); fraud involving illegal distributions and delinquencies in filing periodic 
reports with the Commission are most common among the PinkSheets. In short, the lower listing standards on NASDAQ relative to NYSE are associated with higher levels of financial fraud, insider trading and trading based market manipulation. Likewise, the lower listing standards on the PinkSheets are associated with a higher incidence of illegal distributions and improper and incomplete reporting to the SEC.

Similar to the experience of PinkSheets in the U.S., Table 1 shows there are a pronounced number of cases involving non-listed companies carrying out illegal distributions in Canada. Litigation involving illegal distributions is less common in the U.K. than Canada, which may be explained by the role of the nominated advisors (NOMAD) in the U.K., particularly in the NOMAD’s role for obtaining an AIM listing, as discussed above. ${ }^{16}$

Table 1 clearly highlights the importance of fraud to investors. Perhaps most notably, financial fraud comprises $7.79 \%$ of NASDAQ listings and $2.01 \%$ of NYSE companies. Financial fraud cases involve penalties (from the SEC as well as loss in shareholder value due to reputation and other things) that on average amount to $41 \%$ of a stock's value (Karpoff et al., 2008b). The differences in the frequency of fraud across NYSE and NASDAQ there imply an expected cost of $3.2 \%$ of the value of a NASDAQ listing and $0.8 \%$ of the value of a NYSE listing. Given the absence of reporting of differences in fraud across exchanges, it is unclear whether or not investors take this into account for their investment and/or pricing decisions.

\footnotetext{
16 See also Financial Services Authority (2002). There is some anecdotal evidence of improper conduct among NOMADs, but no such evidence in the FSA case records of NOMAD misconduct.
} 


\section{Table 1. Summary Statistics and Comparison of Proportions Tests}

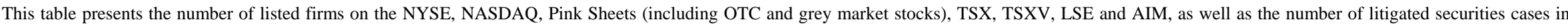

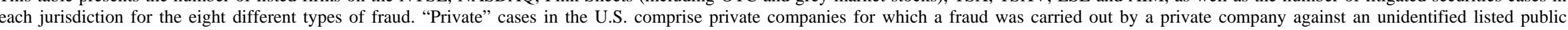

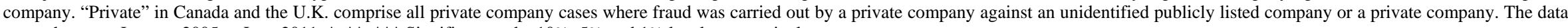
cover the years January 2005 to June 2011. *, **, *** Significant at the $10 \%, 5 \%$ and $1 \%$ levels, respectively.

\begin{tabular}{|c|c|c|c|c|c|c|c|c|c|c|c|c|c|c|c|c|c|c|c|c|}
\hline \multicolumn{21}{|c|}{ Panel A. Summary Statistics } \\
\hline & & \multirow[t]{2}{*}{$\begin{array}{c}\text { Average } \\
\text { Number } \\
\text { Listed } \\
\text { Firms }\end{array}$} & \multicolumn{2}{|c|}{$\begin{array}{l}\text { Total Cases } \\
\text { January } 2005 \text { - } \\
\text { June } 2011\end{array}$} & \multicolumn{2}{|c|}{$\begin{array}{l}\text { Financial } \\
\text { Fraud }\end{array}$} & \multicolumn{2}{|c|}{$\begin{array}{l}\text { Other Fraudulent } \\
\text { Misrepresentation } \\
\text { and disclosure }\end{array}$} & \multicolumn{2}{|c|}{$\begin{array}{c}\text { Illegal } \\
\text { Distribution }\end{array}$} & \multicolumn{2}{|c|}{ Bribery } & \multicolumn{2}{|c|}{$\begin{array}{l}\text { Pump and } \\
\text { Dump }\end{array}$} & \multicolumn{2}{|c|}{$\begin{array}{c}\text { Wash / } \\
\text { Matched / } \\
\text { Improper Trade } \\
\text { / Marking the } \\
\text { Close }\end{array}$} & \multicolumn{2}{|c|}{ Insider Trading } & \multicolumn{2}{|c|}{$\begin{array}{l}\text { Delinquent in } \\
\text { its periodic } \\
\text { filings with the } \\
\text { Commission }\end{array}$} \\
\hline & & & \# & $\%$ & \# & $\%$ & \# & $\%$ & \# & $\%$ & \# & $\%$ & \# & $\%$ & \# & $\%$ & \# & $\%$ & \# & $\%$ \\
\hline (1) & NYSE & 2392 & 290 & $12.12 \%$ & 48 & $2.01 \%$ & 31 & $1.30 \%$ & 34 & $1.42 \%$ & 15 & $0.63 \%$ & 12 & $0.50 \%$ & 47 & $1.96 \%$ & 98 & $4.10 \%$ & 5 & $0.21 \%$ \\
\hline (2) & NASDAQ & 2953 & 867 & $29.36 \%$ & 230 & $7.79 \%$ & 142 & $4.81 \%$ & 47 & $1.59 \%$ & 13 & $0.44 \%$ & 31 & $1.05 \%$ & 82 & $2.78 \%$ & 301 & $10.19 \%$ & 21 & $0.71 \%$ \\
\hline (3) & Pink Sheets & 5667 & 1880 & $33.17 \%$ & 159 & $2.81 \%$ & 212 & $3.74 \%$ & 178 & $3.14 \%$ & 0 & $0.00 \%$ & 151 & $2.66 \%$ & 20 & $0.35 \%$ & 12 & $0.21 \%$ & 1148 & $20.26 \%$ \\
\hline (4) & TSX & 1560 & 33 & $2.12 \%$ & 6 & $0.38 \%$ & 23 & $1.47 \%$ & 3 & $0.19 \%$ & 0 & $0.00 \%$ & 0 & $0.00 \%$ & 0 & $0.00 \%$ & 1 & $0.06 \%$ & 0 & $0.00 \%$ \\
\hline (5) & TSXV & 2333 & 15 & $0.64 \%$ & 4 & $0.17 \%$ & 2 & $0.09 \%$ & 9 & $0.39 \%$ & 0 & $0.00 \%$ & 0 & $0.00 \%$ & 0 & $0.00 \%$ & 0 & $0.00 \%$ & 0 & $0.00 \%$ \\
\hline (6) & LSE & 1549 & 40 & $2.58 \%$ & 4 & $0.26 \%$ & 11 & $0.71 \%$ & 6 & $0.39 \%$ & 0 & $0.00 \%$ & 4 & $0.26 \%$ & 5 & $0.32 \%$ & 8 & $0.52 \%$ & 2 & $0.13 \%$ \\
\hline (7) & AIM & 1452 & 9 & $0.62 \%$ & 0 & $0.00 \%$ & 1 & $0.07 \%$ & 0 & $0.00 \%$ & 0 & $0.00 \%$ & 0 & $0.00 \%$ & 1 & $0.07 \%$ & 7 & $0.48 \%$ & 0 & $0.00 \%$ \\
\hline (8) & Private - US & 5345 & 95 & $1.78 \%$ & 19 & $0.36 \%$ & 36 & $0.67 \%$ & 18 & $0.34 \%$ & 0 & $0.00 \%$ & 7 & $0.13 \%$ & 7 & $0.13 \%$ & 6 & $0.11 \%$ & 2 & $0.04 \%$ \\
\hline (9) & Private - Can & 3893 & 567 & $14.56 \%$ & 28 & $0.72 \%$ & 136 & $3.49 \%$ & 379 & $9.74 \%$ & 0 & $0.00 \%$ & 1 & $0.03 \%$ & 19 & $0.49 \%$ & 4 & $0.10 \%$ & 0 & $0.00 \%$ \\
\hline (10) & Private - UK & 3001 & 390 & $13.00 \%$ & 86 & $2.87 \%$ & 138 & $4.60 \%$ & 85 & $2.83 \%$ & 0 & $0.00 \%$ & 7 & $0.23 \%$ & 17 & $0.57 \%$ & 39 & $1.30 \%$ & 18 & $0.60 \%$ \\
\hline
\end{tabular}

\section{Panel B. Comparison of Proportions Tests}

\begin{tabular}{|c|c|c|c|c|c|c|c|c|c|}
\hline 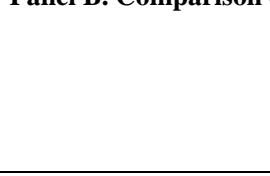 & $\begin{array}{c}\text { Total Cases } \\
\text { January } 2005 \text { - } \\
\text { June } 2011\end{array}$ & $\begin{array}{c}\text { Financial } \\
\text { Fraud }\end{array}$ & $\begin{array}{l}\text { Other Fraudulent } \\
\text { Misrepresentation } \\
\text { and disclosure }\end{array}$ & $\begin{array}{c}\text { Illegal } \\
\text { Distribution }\end{array}$ & Bribery & $\begin{array}{l}\text { Pump and } \\
\text { Dump }\end{array}$ & $\begin{array}{c}\text { Wash / } \\
\text { Matched / } \\
\text { Improper Trade } \\
\text { / Marking the } \\
\text { Close }\end{array}$ & Insider Trading & $\begin{array}{l}\text { Delinquent in } \\
\text { its periodic } \\
\text { filings with the } \\
\text { Commission }\end{array}$ \\
\hline (1) versus '(2) & $\mathrm{p}<=0.000^{* * *}$ & $\mathrm{p}<=0.000^{* * *}$ & $\mathrm{p}<=0.000^{* * *}$ & $\mathrm{p}<=0.613$ & $\mathrm{p}<=0.347$ & $\mathrm{p}<=0.027 * *$ & $\mathrm{p}<=0.054^{*}$ & $\mathrm{p}<=0.000^{* * *}$ & $\mathrm{p}<=0.000^{* * *}$ \\
\hline (1) versus '(3) & $\mathrm{p}<=0.000^{* * *}$ & $\mathrm{p}<=0.902$ & $\mathrm{p}<=0.000^{* * *}$ & $\mathrm{p}<=0.000^{* * *}$ & $\mathrm{p}<=0.000^{* * *}$ & $\mathrm{p}<=0.000^{* * *}$ & $\mathrm{p}<=0.000^{* * *}$ & $\mathrm{p}<=0.000^{* * *}$ & $\mathrm{p}<=0.000^{* * *}$ \\
\hline (4) versus '(5) & $\mathrm{p}<=0.000^{* * *}$ & $\mathrm{p}<=0.198$ & $\mathrm{p}<=0.000^{* * *}$ & $<=0.286$ & $\mathrm{p}<=1.000$ & $\mathrm{p}<=1.000$ & $\mathrm{p}<=1.000$ & $\mathrm{p}<=0.221$ & $\mathrm{p}<=1.000$ \\
\hline (6) versus '(7) & $\mathrm{p}<=0.000^{* * *}$ & $\mathrm{p}<=0.000^{* * *}$ & $\mathrm{p}<=0.000^{* * *}$ & $\mathrm{p}<=0.030^{* *}$ & $\mathrm{p}<=0.000^{* * *}$ & $\mathrm{p}<=0.053^{*}$ & $\mathrm{p}<=0.120$ & $\mathrm{p}<=0.894$ & $\mathrm{p}<=0.171$ \\
\hline All US versus All Canada & $\mathrm{p}<=0.000^{* * *}$ & $\mathrm{p}<=0.000^{* * *}$ & $\mathrm{p}<=0.000^{* * *}$ & $\mathrm{p}<=0.000^{* * *}$ & $\mathrm{p}<=0.000^{* * *}$ & $\mathrm{p}<=0.000^{* * *}$ & $\mathrm{p}<=0.000^{* * *}$ & $\mathrm{p}<=0.000^{* * *}$ & $\mathrm{p}<=0.000^{* * *}$ \\
\hline All US versus All UK & $\mathrm{p}<=0.000^{* * *}$ & $\mathrm{p}<=0.000^{* * *}$ & $\mathrm{p}<=0.000^{* * *}$ & $\mathrm{p}<=0.000^{* * *}$ & $\mathrm{p}<=0.000^{* * *}$ & $\mathrm{p}<=0.000^{* * *}$ & $\mathrm{p}<=0.000^{* * *}$ & $\mathrm{p}<=0.000^{* * *}$ & $\mathrm{p}<=0.000^{* * *}$ \\
\hline $\begin{array}{l}\text { All Canada versus All } \\
\text { UK }\end{array}$ & $\mathrm{p}<=0.000^{* * *}$ & $\mathrm{p}<=0.000^{* * *}$ & $\mathrm{p}<=0.000^{* * *}$ & $\mathrm{p}<=0.000^{* * *}$ & Not Applicable & $\mathrm{p}<=0.000^{* * *}$ & $\mathrm{p}<=0.000^{* * *}$ & $\mathrm{p}<=0.000^{* * *}$ & $\mathrm{p}<=0.000^{* * *}$ \\
\hline
\end{tabular}




\section{Regression Analyses}

This section provides more formal tests with regression analyses to ascertain, in a multivariate setting, whether the total number of fraud cases and the total number of different types of fraud cases are more likely to be observed on different exchanges. We run a series of regressions to predict the frequency of fraud litigation as a function of listing standards, securities commission/country enforcement effects, and exchange effects and timing. For listing standards we use minimum capitalization as required by the exchange, and a dummy variable for the NOMAD requirement on AIM. For securities commission/country enforcement effects we include dummy variables for the CSA and FSA and exclude a dummy for the SEC to avoid perfect collinearity. For market effects we include variables for the number of listed companies on the exchange/year, the average size (market capitalization) of the firms on the exchange in each year, the average market/book value of the firms on the exchange in each year, and the index return in the prior year prior.

To test the proposition that fraud differs across exchanges due to the characteristics of the exchange and not only market conditions and/or characteristics of companies listed on the exchange, we transformed the firm-level data of 4,190 fraud cases into an exchange-year pooled dataset of 49 observations comprised of 7 exchanges (NYSE, NASAQ, PinkSheets, TSX, TSXV, LSE, and AIM) and 7 years (2005-2011). We report the summary statistics (means, medians, standard deviation, minimum and maximum values) from the pooled dataset in Table 2.

Table 2 shows that for an average exchange-year, there are 64 cases in total, of which 9 involve financial disclosures, 9 are non-financial fraudulent disclosure, 6 involve illegal 
distributions, 1 involves bribery, 4 involve pump and dump schemes, 3 involve wash trades, 9 involve insider trading, and 24 involve delinquent filings. The average market/book on an exchange-year is 19.106, which is quite large as a result of the PinkSheet listings. The average index return over the years is $4 \%$.

One of the main variables of interest is the proxy for listing standards. We use the minimum float requirements for that purpose. Unlike Canada and the U.S., we note that minimum float is not uniquely defined on the LSE, as discussed above, so we proxy minimum float by minimum capitalization; adjustments to this proxy based on the $25 \%$ float requirement discussed above did not significantly influence our findings discussed below. Also, we note that on some exchanges there are multiple tiers of listing, such as the LSE as discussed above. We are unable to treat different tiers in our pooled dataset as distinct markets since there does not exist market statistics for the listed companies within each tier (market capitalization and/or other trading data are not reported by tier, and likewise firm-specific data such as numbers of listed companies in a tier and/or market/book ratios etc. are not reported by tier). Nevertheless, the distinctions within different tiers on an exchange are very small compared to the differences across exchanges, and our proxy for listing standards by minimum float is not materially different by tiers. The average minimum float is US\$18.017 million, and the standard deviation is US\$34.467 million.

We show the regression results in Table 3 for all cases in Panel A, the subset of cases with sanctions in Panel B, and the subset of cases from NYSE, NASDAQ, and the PinkSheets in Panel C. All of the regressions are estimated with 2-way clustering of standard errors by country 
and time (Petersen, 2009). The use of clustered standard errors lowers the statistical significance of some of the estimates relative to not clustering.

Table 3 Panel A shows that minimum capitalization listing standards significantly impacts the frequency of total fraud, and this effect is significant at the $5 \%$ level. In particular, an increase in listing standards by 1-standard deviation (18.017 million) is associated with 17.56 fewer cases per month. Given the median number of cases per exchange-year is 64, this represents a drop by $27.4 \%$ relative to the average. In other words, the effect is economically significant. In the subsample of cases with sanctions (Panel B), the effect is slightly larger at 16.68 fewer cased per month for a 1-standard deviation drop. But given there are only an average of 36.5 cases per month, this represents a percentage drop by $45.8 \%$ relative to the average. Finally, in the subsample of U.S. cases from NYSE, NASDAQ, and the PinkSheets in Panel $\mathrm{C}$, the drop in the total number of cases for a 1-standard deviation change in listing standards is 20.3 cases, or $14 \%$ of the 144.7 cases per month in the U.S. Overall, the data are therefore consistent with the notion that higher listing standards on an exchange are associated with fewer incidences of fraud, and this effect is statistically and economically significant, and robust to different subsets of the data.

Regarding the different types of fraud, higher minimum capitalization is associated with less frequent financial fraud in each of Panels A, B, and C, and this effect is statistically significant at the $1 \%$ level in Panels A and B, and at the $10 \%$ level in Panel C. The economic significance is such that a 1-standard deviation increase in minimum capitalization is associated 
with a reduction in financial fraud by 6.1 cases per month, which is a reduction of $66 \%$ relative to the average number (9.2) of financial fraud cases in each exchange-month.

Higher minimum capitalization is likewise associated with less frequent pump and dump cases and fewer delinquencies in filing with the Commission in Panel B for the subsample of cases involving sanctions, and these effects are significant at the $10 \%$ and $5 \%$ levels, respectively. The economic significance is such that a 1-standard deviation increase in minimum capitalization is associated with a reduction by 4.4 pump and dump cases (which is $35.5 \%$ relative to the average exchange-year) and a reduction by 12.7 delinquent filings cases (which is a reduction by $52.8 \%$ relative to the average exchange-year).

Note that each of the Panels A, B, and C show higher minimum capitalization is associated with higher levels of bribery. Recall from Table 1 that only the NYSE firms were discovered bribing foreign officials, and hence we may infer that this effect is related to the fact higher listing standards mitigate the presence of smaller domestic-only companies without an interest bribing foreign officials. The economic significance is large as well: a 1-standard deviation reduction in minimum capitalization reduces the probability of bribery by 1.26 cases per exchange-month, which is $220 \%$ of the average number $(0.571)$ of bribery cases per exchange-month.

Unlike minimum capitalization, the NOMAD listing requirement shows very little evidence of being associated with fraud. The only evidence comes from the bribery cases in Panel A, but this effect is not robust in the subsample of sanctioned cases in Panel B. Moreover, 
there is evidence of more frequent delinquent filings with the commission cases in both Panels A and B. Overall, therefore, the data appear to be most consistent with the view that NOMAD requirements do very little, if anything, to mitigate fraud.

The country variables in Table 3 show the Canadian Securities Administrator (CSA) and the Financial Services Authority (FSA) in the U.K. are less effective than the Securities and Exchange Commission (SEC) in the U.S. in detecting and litigating fraud. On average, the CSA and FSA respectively initiate 86 and 82 fewer cases, and have 101 and 103 fewer sanctioned cases. Put differently, in any given year the SEC initiates more than $130 \%$ of cases than does the CSA or FSA, and has over $280 \%$ more sanctions than does the CSA or FSA. These differences are significant at the $1 \%$ level for the FSA for both initiated cases and sanctions, and at the $1 \%$ level for initiated cases and at the 5\% level for sanctions for the CSA. Similarly pronounced differences in terms of both economic and statistical significance exist in the data between the CSA and FSA vis-à-vis the SEC for all the specific types of fraud, with the exception of illegal distributions, pump-and-dump schemes, and delinquent filings.

The control variables in Table 3 are for the most part significant in ways one would expect. First, when there are more companies listed in each exchange-year, there are a significantly greater total number of fraud cases, as well as more illegal distributions, pump and dump cases, and cases involving delinquent filings, as expected. More listed companies are associated with fewer bribery cases (which could reflect stronger market conditions and less of a need to bribe) and fewer insider trading cases (which could reflect a lower proportion of insiders with more companies, or less proprietary knowledge among insiders). 
Second, the data indicate that the average size of companies is rather unrelated to fraud. It is noteworthy that average firm size is unrelated to fraud, while minimum size requirements in terms of capitalization are related to fraud, as indicated above. The absence of an average size firm effect taken together with a significant minimum capitalization effect suggests the role of listing standards is to keep the left-tail of the distribution out of the population and thereby reduce the likelihood of fraud.

Third, we control for industry effects by using the average market/book ratio in each exchange-year. High market/book values are associated with high-tech companies and those with relatively more intangible assets, and companies with significant with growth options and hence more pronounced agency problems. The data indicate market/book values are associated with more total fraud in Panel A and C, although this effect is insignificant for total sanctions in Panel B. There some differences in the effect of market/book values on fraud in the subsamples. In the full sample in Panel A and in the sample of sanctioned cases in Panel B, market/book is positively associated with more fraudulent misrepresentation and disclosure. In Panel C, market/book is positively associated with bribery and delinquent filings. In the subsample of sanctioned cases, market/book is negatively associated with financial fraud and delinquent filings. We do not have strong explanations for these latter two results, except the possibility that sanctions are harder to secure for certain types of cases in industries with relatively more intangible assets. 


\section{Table 2. Variable Definitions and Summary Statistics}

This table defines the variables used in the regressions in Table 3 and provides summary statistics. The sample covers 4,190 cases initiated by securities commissions in Canada, the U.K. and the U.S. over the period January 2005 to June 2011. The panel comprises 49 observations for 7 exchanges (NYSE, NASDAQ, PinkSheets, TSX, TSXV, LSE, and AIM) and 7 years (2005-2011). The Canadian data are derived from http://www.securities-administrators.ca/. The U.K. data are derived from http://www.fsa.gov.uk/Pages/library/index.shtml. The SEC data are derived from http://search.sec.gov/secgov/index.jsp\#queryResultsTop.

\begin{tabular}{|c|c|c|c|c|c|c|}
\hline Variable & Definition & Mean & Median & $\begin{array}{c}\text { Standard } \\
\text { Deviation }\end{array}$ & Minimum & Maximum \\
\hline Total Fraud & The total number of fraud cases in each exchange-year. & 63.959 & 8 & 99.647 & 0 & 379 \\
\hline Financial Fraud & The total number of financial fraud cases in each exchange-year. & 9.204 & 1 & 13.299 & 0 & 53 \\
\hline $\begin{array}{l}\text { Non-Financial Fraudulent } \\
\text { Disclosure }\end{array}$ & The total number of non-financial disclosure fraud cases in each exchange-year. & 8.612 & 2 & 17.184 & 0 & 81 \\
\hline Illegal Distribution & The total number of illegal distribution cases in each exchange-year. & 5.653 & 1 & 10.505 & 0 & 44 \\
\hline Bribery & The total number of bribery cases in each exchange-year. & 0.571 & 0 & 1.275 & 0 & 7 \\
\hline Pump and Dump & The total number of pump-and-dump cases in each exchange-year. & 4.041 & 0 & 7.903 & 0 & 25 \\
\hline $\begin{array}{l}\text { Wash / Matched / } \\
\text { Improper Trade / } \\
\text { Marking the Close }\end{array}$ & $\begin{array}{l}\text { The total number of wash trade, improper trade, and marking the close fraud cases in each exchange- } \\
\text { year. }\end{array}$ & 3.163 & 0 & 11.033 & 0 & 69 \\
\hline Insider Trading & The total number of insider trading cases in each exchange-year. & 8.714 & 1 & 17.865 & 0 & 94 \\
\hline $\begin{array}{l}\text { Delinquent Filings with } \\
\text { the Commission }\end{array}$ & The total number of delinquent filing cases in each exchange-year. & 24.000 & 0 & 64.954 & 0 & 286 \\
\hline Minimum Float & The minimum float required on the exchange (proxied by minimum capitalization for the LSE). & 18.017 & 1.12 & 34.467 & 0 & 100 \\
\hline NOMAD & A dummy variable equal to 1 for AIM listings to account for the NOMAD requirement. & 0.143 & 0 & 0.354 & 0 & 1 \\
\hline CSA & A dummy variable equal to 1 for CSA cases. & 0.265 & 0 & 0.446 & 0 & 1 \\
\hline FSA & A dummy variable equal to 1 for FSA cases. & 0.286 & 0 & 0.456 & 0 & 1 \\
\hline $\begin{array}{l}\text { Number of Listed } \\
\text { Companies }\end{array}$ & The total number of listed companies each exchange-year. & $2,543.816$ & 2,270 & 1368.534 & 1,194 & 6,135 \\
\hline $\begin{array}{l}\text { Average Size of Listed } \\
\text { Companies }\end{array}$ & The average market capitalization of the companies in each exchange-year in millions of USD. & 1469.739 & 1064.273 & 1962.887 & 1.547 & 6813.597 \\
\hline $\begin{array}{l}\text { Average Market / Book } \\
\text { of Listed Companies }\end{array}$ & The average market / book value of listed companies in each exchange year. & 19.106 & 4.489 & 52.439 & 1.726 & 254.505 \\
\hline Index Return & The market-specific index return in each exchange-year. & 0.039 & 0.85 & 0.187 & -0.386 & 0.297 \\
\hline
\end{tabular}


Table 3. Regression Analyses

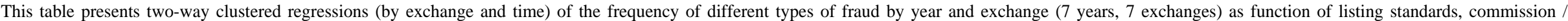

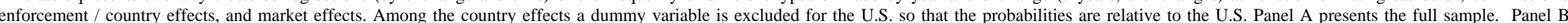
presents the subsample of cases with sanctions only. Panel C presents the subsample from NYSE, NASDAQ, and PinkSheets only. *, **, *** Significant at the $10 \%$, $5 \%$ and $1 \%$ levels, respectively.

\begin{tabular}{|c|c|c|c|c|c|c|c|c|c|c|c|c|c|c|c|c|c|c|}
\hline \multirow[t]{2}{*}{ Panel A. Full Sample } & \multicolumn{2}{|c|}{ Total Fraud } & \multicolumn{2}{|c|}{ Financial Fraud } & \multicolumn{2}{|c|}{$\begin{array}{l}\text { Fraudulent } \\
\text { Misrepresentation } \\
\text { and disclosure }\end{array}$} & \multicolumn{2}{|c|}{ Illegal Distribution } & \multicolumn{2}{|c|}{ Bribery } & \multicolumn{2}{|c|}{ Pump and Dump } & \multicolumn{2}{|c|}{$\begin{array}{l}\text { Wash / Matched / } \\
\text { Improper Trade / } \\
\text { Marking the Close }\end{array}$} & \multicolumn{2}{|c|}{ Insider Trading } & \multicolumn{2}{|c|}{$\begin{array}{l}\text { Delinquent in its } \\
\text { periodic filings with } \\
\text { the Commission }\end{array}$} \\
\hline & $\begin{array}{c}\text { Coeffici } \\
\text { ent }\end{array}$ & t-statistic & $\begin{array}{c}\text { Coeffici } \\
\text { ent }\end{array}$ & $\begin{array}{c}\mathrm{t}- \\
\text { statistic }\end{array}$ & $\begin{array}{c}\text { Coeffici } \\
\text { ent }\end{array}$ & $\begin{array}{c}\mathrm{t}- \\
\text { statistic }\end{array}$ & $\begin{array}{c}\text { Coeffici } \\
\text { ent }\end{array}$ & $\begin{array}{c}\mathrm{t}- \\
\text { statistic }\end{array}$ & $\begin{array}{c}\text { Coeffi } \\
\text { cient }\end{array}$ & $\begin{array}{c}\mathrm{t}- \\
\text { statistic }\end{array}$ & $\begin{array}{c}\text { Coeffi } \\
\text { cient }\end{array}$ & $\begin{array}{c}\mathrm{t}- \\
\text { statistic }\end{array}$ & $\begin{array}{c}\text { Coeffici } \\
\text { ent }\end{array}$ & $\begin{array}{c}\mathrm{t}- \\
\text { statisti } \\
\mathrm{C}\end{array}$ & $\begin{array}{c}\text { Coeffici } \\
\text { ent }\end{array}$ & $\begin{array}{c}\mathrm{t}- \\
\text { statistic }\end{array}$ & $\begin{array}{c}\text { Coeffici } \\
\text { ent }\end{array}$ & t-statistic \\
\hline \multicolumn{19}{|l|}{$\underline{\text { Listing Standards }}$} \\
\hline $\begin{array}{c}\text { Minimum } \\
\text { Capitalization }\end{array}$ & -0.975 & $-2.24 * *$ & -0.177 & $-3.56^{* * *}$ & -0.231 & -1.41 & 0.045 & 0.46 & 0.037 & $4.73^{* * *}$ & -0.077 & -1.45 & -0.052 & -0.72 & -0.145 & -0.64 & -0.374 & -1.31 \\
\hline \multicolumn{19}{|l|}{$\frac{\begin{array}{c}\text { Commission / } \\
\text { Country Enforcement }\end{array}}{\text { Effects }}$} \\
\hline$\overline{\mathrm{CSA}}$ & -85.896 & $-4.24 * * *$ & -29.409 & $-1.72 *$ & -20.583 & $-2.01^{* *}$ & 1.728 & 0.36 & -1.725 & $-2.19 * *$ & 0.584 & 0.42 & -9.743 & $-1.81 *$ & -48.516 & $-5.31 * * *$ & 21.767 & 1.07 \\
\hline FSA & -82.050 & $-3.32 * * *$ & -28.935 & $-1.80 *$ & -22.807 & $-1.85^{*}$ & 5.271 & 0.96 & -1.012 & $-1.80^{*}$ & 1.039 & 0.48 & -10.279 & -1.47 & -48.442 & $-4.11^{* * *}$ & 23.115 & 1.15 \\
\hline \multicolumn{19}{|l|}{$\underline{\text { Market Effects }}$} \\
\hline $\begin{array}{l}\text { Number of Listed } \\
\text { Companies }\end{array}$ & 0.032 & $3.84^{* * *}$ & -0.001 & -0.19 & -0.0004 & -0.39 & 0.007 & $3.13^{* * *}$ & -0.001 & $-1.74 *$ & 0.006 & $6.79 * * *$ & -0.001 & -0.37 & -0.012 & $-3.28 * * *$ & 0.035 & $4.09 * * *$ \\
\hline $\begin{array}{l}\text { Average Size of } \\
\text { Listed Companies }\end{array}$ & 0.007 & 0.73 & -0.001 & -0.33 & 0.001 & 0.54 & 0.000 & -0.15 & -0.001 & $-2.10^{* *}$ & 0.001 & 1.56 & 0.001 & 1.53 & -0.002 & -0.60 & 0.008 & 1.61 \\
\hline $\begin{array}{c}\text { Average } \\
\text { Market/Book of } \\
\text { Listed Companies }\end{array}$ & 0.604 & $53.99 * * *$ & -0.020 & -0.64 & 0.073 & $1.75^{*}$ & -0.006 & -0.23 & 0.001 & 0.27 & 0.015 & 1.33 & -0.027 & -1.45 & -0.004 & -0.07 & 0.573 & $8.95^{* * *}$ \\
\hline Index Return & 31.007 & 1.49 & 5.572 & $1.86^{*}$ & -0.057 & 0 & 7.532 & 0.85 & 0.593 & 1.54 & -0.011 & -0.01 & 0.299 & 0.09 & 3.124 & 0.27 & 13.956 & 0.67 \\
\hline Constant & 20.221 & 0.82 & 32.916 & 1.10 & 22.964 & $1.78^{*}$ & -15.260 & $-1.78^{*}$ & 2.921 & $2.00^{* *}$ & $\begin{array}{c}- \\
12.196\end{array}$ & $-3.61^{* * *}$ & 10.960 & 1.39 & 73.994 & $4.85 * *$ & -96.078 & $-2.77^{* * *}$ \\
\hline \# Observations & & 9 & & & & & & & & 19 & & 49 & & & & & & \\
\hline Adj R2 & & 19 & & & & & & & & 496 & & 875 & 0. & & & & & \\
\hline \multicolumn{19}{|c|}{ Panel B. Subsample of Cases with Sanctions } \\
\hline & \multicolumn{2}{|c|}{ Total Fraud } & \multicolumn{2}{|c|}{ Financial Fraud } & \multicolumn{2}{|c|}{$\begin{array}{c}\text { Fraudulent } \\
\text { Misrepresentation } \\
\text { and disclosure }\end{array}$} & \multicolumn{2}{|c|}{ Illegal Distribution } & \multicolumn{2}{|c|}{ Bribery } & \multicolumn{2}{|c|}{ Pump and Dump } & \multicolumn{2}{|c|}{$\begin{array}{l}\text { Wash / Matched / } \\
\text { Improper Trade / } \\
\text { Marking the Close }\end{array}$} & \multicolumn{2}{|c|}{ Insider Trading } & \multicolumn{2}{|c|}{$\begin{array}{l}\text { Delinquent in its } \\
\text { periodic filings with } \\
\text { the Commission }\end{array}$} \\
\hline & $\begin{array}{c}\text { Coeffici } \\
\text { ent }\end{array}$ & t-statistic & $\begin{array}{l}\text { Coeffici } \\
\text { ent }\end{array}$ & $\begin{array}{c}\mathrm{t}- \\
\text { statistic }\end{array}$ & $\begin{array}{c}\text { Coeffici } \\
\text { ent }\end{array}$ & $\begin{array}{c}\mathrm{t}- \\
\text { statistic }\end{array}$ & $\begin{array}{c}\text { Coeffici } \\
\text { ent }\end{array}$ & $\begin{array}{c}\mathrm{t}- \\
\text { statistic }\end{array}$ & $\begin{array}{l}\text { Coeffi } \\
\text { cient }\end{array}$ & $\begin{array}{c}\mathrm{t}- \\
\text { statistic }\end{array}$ & $\begin{array}{c}\text { Coeffi } \\
\text { cient }\end{array}$ & $\begin{array}{c}\mathrm{t}- \\
\text { statistic }\end{array}$ & $\begin{array}{c}\text { Coeffici } \\
\text { ent }\end{array}$ & $\begin{array}{c}\mathrm{t}- \\
\text { statisti } \\
\mathrm{C}\end{array}$ & $\begin{array}{c}\text { Coeffici } \\
\text { ent }\end{array}$ & $\begin{array}{c}\mathrm{t}- \\
\text { statistic }\end{array}$ & $\begin{array}{c}\text { Coeffici } \\
\text { ent }\end{array}$ & t-statistic \\
\hline \multicolumn{19}{|l|}{ Listing Standards } \\
\hline $\begin{array}{l}\text { Minimum } \\
\text { Capitalization }\end{array}$ & -0.926 & $-2.83^{* * *}$ & -0.186 & $-4.14 * * *$ & -0.225 & -1.57 & 0.087 & 1.02 & 0.019 & $4.29 * * *$ & -0.045 & $-1.73^{*}$ & -0.045 & -0.65 & -0.163 & -0.71 & -0.368 & $-2.10^{* *}$ \\
\hline NOMAD & 4.406 & 0.35 & -2.318 & -0.5 & -0.835 & -0.33 & -4.242 & -0.98 & -0.687 & -1.57 & 0.536 & 0.46 & 0.366 & 0.46 & -3.610 & -0.48 & 15.196 & $2.40^{* *}$ \\
\hline
\end{tabular}




\begin{tabular}{|c|c|c|c|c|c|c|c|c|c|c|c|c|c|c|c|c|c|c|}
\hline \multirow[t]{2}{*}{$\begin{array}{l}\text { Table } 3 \text { Panel B } \\
\text { (Continued) }\end{array}$} & \multicolumn{2}{|c|}{ Total Fraud } & \multicolumn{2}{|c|}{ Financial Fraud } & \multicolumn{2}{|c|}{$\begin{array}{l}\text { Fraudulent } \\
\text { Misrepresentation } \\
\text { and disclosure }\end{array}$} & \multicolumn{2}{|c|}{ Illegal Distribution } & \multicolumn{2}{|c|}{ Bribery } & \multicolumn{2}{|c|}{ Pump and Dump } & \multicolumn{2}{|c|}{$\begin{array}{l}\text { Wash / Matched / } \\
\text { Improper Trade / } \\
\text { Marking the Close }\end{array}$} & \multicolumn{2}{|c|}{ Insider Trading } & \multicolumn{2}{|c|}{$\begin{array}{l}\text { Delinquent in its } \\
\text { periodic filings with } \\
\text { the Commission }\end{array}$} \\
\hline & $\begin{array}{c}\text { Coeffici } \\
\text { ent }\end{array}$ & t-statistic & $\begin{array}{c}\text { Coeffici } \\
\text { ent }\end{array}$ & $\begin{array}{c}\mathrm{t}- \\
\text { statistic }\end{array}$ & $\begin{array}{l}\text { Coeffici } \\
\text { ent }\end{array}$ & $\begin{array}{c}\mathrm{t}- \\
\text { statistic }\end{array}$ & $\begin{array}{c}\text { Coeffici } \\
\text { ent }\end{array}$ & $\begin{array}{c}\mathrm{t}- \\
\text { statistic }\end{array}$ & $\begin{array}{l}\text { Coeffi } \\
\text { cient }\end{array}$ & $\begin{array}{c}\mathrm{t}- \\
\text { statistic }\end{array}$ & $\begin{array}{l}\text { Coeffi } \\
\text { cient }\end{array}$ & $\begin{array}{c}\mathrm{t}- \\
\text { statistic }\end{array}$ & $\begin{array}{l}\text { Coeffici } \\
\text { ent }\end{array}$ & $\begin{array}{c}\mathrm{t}- \\
\text { statisti } \\
\mathrm{C}\end{array}$ & $\begin{array}{l}\text { Coeffici } \\
\text { ent }\end{array}$ & $\begin{array}{c}\mathrm{t}- \\
\text { statistic }\end{array}$ & $\begin{array}{l}\text { Coeffici } \\
\text { ent }\end{array}$ & t-statistic \\
\hline \multicolumn{19}{|l|}{$\begin{array}{l}\frac{\text { Commission } /}{\text { Country Enforcement }} \\
\text { Effects }\end{array}$} \\
\hline CSA & -100.946 & $-2.54^{* *}$ & -28.698 & $-1.78^{*}$ & -23.359 & $-1.89 *$ & -4.582 & -1.48 & -1.678 & $-2.04 * *$ & -2.806 & -1.54 & -8.667 & $2.03^{* *}$ & -40.220 & $-2.50 * *$ & 9.064 & 0.86 \\
\hline $\begin{array}{c}\text { FSA } \\
\text { Market Effects } \\
\end{array}$ & -103.290 & $-2.59 * * *$ & -28.558 & $-1.91 *$ & -25.484 & $-1.85^{*}$ & -0.285 & -0.06 & -1.309 & $-2.24 * *$ & -2.625 & -1.52 & -9.251 & -1.61 & -40.958 & $-2.38^{* *}$ & 5.180 & 0.50 \\
\hline $\begin{array}{l}\text { Number of Listed } \\
\text { Companies }\end{array}$ & 0.004 & 0.4 & -0.003 & -0.46 & -0.004 & -1.39 & 0.001 & 0.89 & $\begin{array}{c}- \\
0.0005\end{array}$ & -1.56 & 0.001 & 1.64 & -0.001 & -0.95 & -0.010 & $-1.92^{*}$ & 0.020 & $5.32^{* * *}$ \\
\hline $\begin{array}{l}\text { Average Size of } \\
\text { Listed Companies }\end{array}$ & 0.004 & 0.72 & -0.001 & -0.31 & 0.001 & 0.61 & -0.002 & -0.83 & 0.0003 & -1.57 & 0.001 & 0.83 & 0.001 & 0.94 & -0.001 & -0.34 & 0.007 & $2.50^{* *}$ \\
\hline $\begin{array}{c}\text { Average } \\
\text { Market/Book of } \\
\text { Listed Companies }\end{array}$ & -0.129 & -1.37 & -0.052 & $-1.69 *$ & 0.070 & $1.82^{*}$ & 0.002 & 0.08 & 0.000 & 0.09 & -0.012 & -1.15 & -0.013 & -0.74 & 0.0004 & 0.01 & -0.123 & $-1.83^{*}$ \\
\hline Index Return & 22.820 & 0.79 & 7.894 & 1.36 & 0.876 & 0.07 & 11.349 & 1.19 & 0.596 & $1.71^{*}$ & -0.058 & -0.02 & 0.886 & 0.35 & 11.301 & $2.63^{* * *}$ & -10.023 & -1.52 \\
\hline Constant & 93.989 & 1.58 & 34.537 & 1.27 & 31.467 & $1.83^{*}$ & 2.608 & 0.52 & 2.674 & $1.86^{*}$ & 0.318 & 0.09 & 10.779 & $2.11^{* *}$ & 60.031 & $2.57^{* *}$ & -48.425 & $-3.10^{* * *}$ \\
\hline \# Observations & \multicolumn{2}{|c|}{49} & \multicolumn{2}{|c|}{49} & \multicolumn{2}{|c|}{49} & \multicolumn{2}{|c|}{49} & \multicolumn{2}{|c|}{49} & \multicolumn{2}{|c|}{49} & \multicolumn{2}{|c|}{49} & \multicolumn{2}{|c|}{49} & \multicolumn{2}{|c|}{49} \\
\hline Adj R2 & \multicolumn{2}{|c|}{0.698} & \multicolumn{2}{|c|}{0.619} & \multicolumn{2}{|c|}{0.283} & \multicolumn{2}{|c|}{0.235} & \multicolumn{2}{|c|}{0.490} & \multicolumn{2}{|c|}{0.355} & \multicolumn{2}{|c|}{0.112} & \multicolumn{2}{|c|}{0.452} & \multicolumn{2}{|c|}{0.726} \\
\hline
\end{tabular}

Panel C. Subsample from NYSE, NASDAQ, and PinkSheets

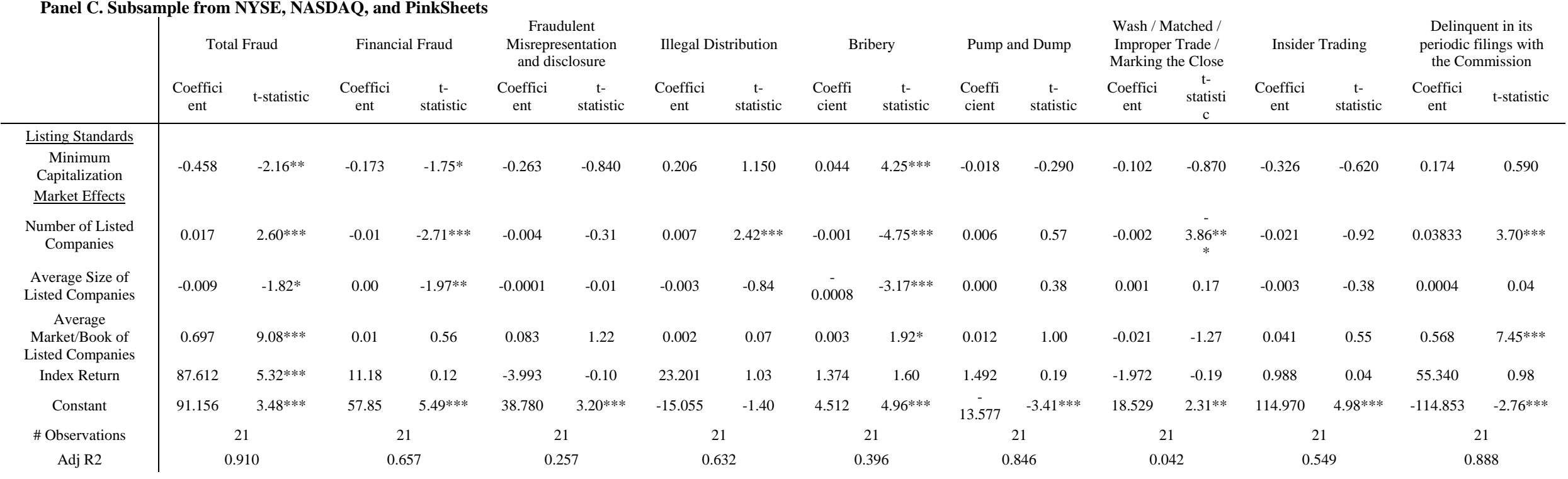




\section{Additional Robustness Checks, Extensions and Future Research}

We considered a number of other robustness checks that are not reported in Table 3. First, we consider other regression methods including but not limited to Poisson regressions. Poisson regressions account for the fact that in the data most exchange-years do not have many cases, and only in a few exchange-years there are a significantly larger number of case (i.e., the distribution of the dependent variable closely resembles a Poisson distribution). In those regressions we found quite similar effects in terms of economic significance, but often had greater statistical significance with the estimates. But because double-clustering of standard errors is not feasible with Poisson regressions, we decided to report the results as seen in Table 3.

Second, we considered other explanatory variables such as different alternatives for market conditions and exchange effects but the results were not materially impacted. The only regressions where findings significantly changed were those in which new variables introduced severe collinearity problems. In our estimates we are unable to incorporate fixed effects across exchanges since some of the variables are time invariant in the pooled sample.

Third, we considered dropping some years, such as 2011 where we have only half the year represented. As well, we considered combining the U.S. subsample in Table 3 Panel C with Canada only, or the U.K. only. In each case, the findings were not materially different.

Fourth, we considered firm-level regressions (unlike the pooled exchange-year level regressions reported in Table 3) in an earlier version of this paper to ascertain the likelihood of 
different types of fraud across exchanges. In those regressions we inferred from the data that differences across exchanges do in fact give rise to differences in fraud propensities. This general inference is consistent with that from Table 3: fraud is observed with different frequency on different exchanges. Therefore, it naturally follows that market participants, especially investors, should have access to this information through exchanges and their regulators posting statistics on fraud on an exchange-by-exchange basis. This implication from the data is discussed further below.

The most significant limitation of our empirical analysis is that we do not observe changes in listing standards over time in our sample. Further research could explore such changes if and when they occur in the future. Nevertheless, we note that the differences in means and medians in fraud across the exchanges we observe is extremely large (Table 1) and robust to controls for time, market conditions, firm characteristics such as size and market / book value, etc. (Table 3). As we have mentioned, while there are massive differences in listing rules, there are much less pronounced regulatory and institutional differences between Canada, the U.K. and the U.S. in terms of legal origin and securities regulation (La Porta et al., 1997, 1998, 2006)., exchange trading rules (Cumming et al., 2011), surveillance (Cumming and Johan, 2008), and enforcement expenditures (Jackson and Roe, 2009). Therefore, we believe the evidence is strongly consistent with the view that the differences in fraud across exchanges in Canada, the U.K. and the U.S. are best accounted for in terms of listing standards and the accompanying quality of enforcement settings in the different countries. 
Three additional areas could be explored in future research. First, when comparing enforcement across regimes, the underlying legal framework may be the cause of some of the discrepancies. Future research could examine the extent to which differences in private rights give rise to differences in public enforcement from public organizations such as the SEC. Though agency funding across the SEC, FSA and CSA is relatively the same, the significantly higher amount of U.S. private litigation may alert the SEC to investigate certain types of fraud. That is, there may be complementarities between private and public enforcement.

Second, if we are correct in inferring that characteristics of different exchanges lead to different enforcement outcomes, it would be useful to obtain data on agencies' budget figures to see how agencies apportion their enforcement budget across the various exchanges. We were unable to obtain such data for this project, but such data may become available in the future.

Third, future work could consider cultural differences across countries in the spirit of Hofstede’s work (http://geert-hofstede.com/). There are small differences in corruption across Canada, the U.K. and the U.S., but we were unable to tie these differences to the fraud outcomes observed. By considering other countries, there may be further insights (although see the next section below). As a related matter, it is possible that that different media exposure across countries also impacts enforcement. That is, it may be that across the regimes some countries have a stronger "business morality" for which there is a reputational loss related to fines for wrongdoing that the purely financial penalties do not capture. Karpoff et al. (2008a,b) have carried out work in the U.S., but we are unaware of similar work in the other countries. 


\section{Insights from Other Jurisdictions}

In this section we briefly compare reported cases of securities fraud in Brazil, China and Germany. These countries are civil law jurisdictions that represent an interesting comparison between fast-developing nations and well-established industrialized nations.

Financial fraud is rarely litigated in Brazil. Despite recent corporate governance reforms in Brazil ("Novo Mercado” in 2005), Brazil only handed down the first-ever insider trading case ruling in the country in February 2011 (Hoffman, 2011). The case involved insider trading associated with the purchase of a food maker, and two executives were sentenced to community service in lieu of a prison term and fines of approximately US\$200,000. The executives that were sentenced included the former CFO and a former board member of Sadia SA, whereby the acquisition in question enabled Sadia to form the world's largest poultry exporter. The executives had purchased American depositary receipts before the hostile bid to buy their rival in 2006. In addition, the authors of this report and their assistants contacted the CVM (Brazilian Securities Commission) in June 2011 about other cases involving securities fraud in Brazil and failed to get a response after two months. The English version of the CVM webpage appears to be much lighter than the Portuguese version (Securities and Exchange Commission of Brazil, 2011). Moreover, other sources indicate that "[t]he CVM's recommendations on corporate governance are not mandatory, and non-compliance is not subject to punishment. Firms that are at least six months late in filing their annual reports are only placed on a list that is published on 
the CVM's website." ${ }^{17}$ Suffice it to say, enforcement of securities regulation in Brazil is not frequent, exacting or severe. Hence fraud is so rarely observed in Brazil that investor confidence is likewise expected to be at a very low level relative to other markets.

China offers an interesting comparison to Brazil as competing developing nations, both already major players in terms of global presence. Like CVM in Brazil, the Chinese Securities and Regulatory Commission (CSRC) revised its securities laws in 2005. The CSRC reforms were based in part on an international consultation with best practices in other developed countries. Empirical work on corporate fraud in China (Hou and Moore, 2010) shows plenty of litigated cases, representing on average 3.8\% of listed companies per year. Importantly, we note that there are no material differences in listing standards between the Shanghai and Shenzen stock exchanges and likewise there are no material differences in fraud across these two exchanges (Hou and Moore, 2010). At the same time, however, there are significant differences in the detection of fraud and consequences of detecting fraud in terms of market reaction depending on whether or not the company involved has a political connection to the state (Cumming, et al., 2011).

While fraud is commonly detected in some developing countries like China, fraud is rarely detected in other developed countries. One notable example is Germany. The junior Neur Markt exchange appears to have had merely 4 confirmed cases of fraud (Peemöller and Hofmann, 2005) and 25 documented rumors of suspected fraud (Burghof and Hunger, 2003) in its entire history. Coupled with the burst of the DotCom bubble, a lack of confidence among

\footnotetext{
${ }^{17}$ See the Economist Intelligence Unit available at http://www.eiu.com/index.asp?layout=ib3Article\&article $i d=827089267 \&$ country id=1480000148\&pubtypeid=113 2462498\&industry_id $=640001064 \&$ category_id $=\& \mathrm{rf}=0$
} 
market participants in the regulators ability to detect and prosecute fraud led to the demise of the Neur Markt at the end of 2002. In conversations with academics in Germany in 2011, we learned that the regulatory body in Germany appears to have some information on insider trading on the Neur Markt, but are very reluctant to give it away even to academics in Germany. There is no news service or other form of record keeping on fraud and insider trading from the Neur Markt other than that which has been documented by academic studies (Burghof and Hunger, 2003; Peemöller and Hofmann, 2005).

\section{Policy Implications and Recommendations}

Exchange listing standards provide to market participants a signal of the quality of the exchange and the nature of the companies trading on the exchange. Higher listing standards attract more mature companies for which information problems are less pronounced. Exchanges themselves act as a mechanism to signal quality in terms of screening out lower-quality listings. The first-line governance provided by the exchange signals to investors the potential rigor required for appropriate due diligence of issues related to potential fraud. Also, it potentially mitigates the need for time-constrained or less-sophisticated individual investors to carry out their own thorough due diligence of the corporate governance structures for every potential investment. Certification provided by an exchange provides a potentially informative function in the market by certifying the quality of the companies that it lists.

The data in this report suggest recent changes towards lowering listing standards in the U.S., including but not limited to the NASDAQ BX Venture Exchange, are also likely to be 
associated with changes in the extent and type of observed fraud. The findings in this report by themselves do not mean that lower listing standards are inappropriate. However, with these findings we are able to determine the extent to which regulations are violated and do give rise to the following policy recommendations:

\section{Report securities fraud cases committed by companies on an exchange-by-exchange}

basis. The SEC and other securities commissions around the world should report securities fraud committed by companies on an exchange basis. Fraud is an investment risk that investors should incorporate into their valuation considerations. Without appropriate disclosure by securities commissions, investors are not able to systematically and correctly estimate the probability of different types of fraud across different exchanges, and therefore are not able to appropriately price risk and allocate capital in an efficient manner. Currently, there is no exchange or securities commission around the world that makes information on fraud committed by officers of listed companies available to the public and how such statistics differ across different exchanges within the jurisdiction and/or across other jurisdictions. Along with disclosure by securities commissions of fraud committed by companies listed on an exchange, it should be made clear to investors that the extent to which fraud is detected does not necessarily imply that the exchange is failing in its mandate to effort to provide a regulated market for both investors and listings, but rather that securities commissions are actively pursuing wrongdoers on the exchange for the purpose of enhancing exchange quality. One way to report fraud could be to report the difference between the expected level of fraud among publicly traded companies each year (for instance, methods to estimate are provided by 
Wang et al., 2012) and the actual level of detected fraud by exchange. In that way, investors would know the extent to which fraud is being undetected across exchanges and be able to use such information to price accurately stocks and allocate capital. ${ }^{18}$

2. Report securities fraud cases committed by investors trading corporate shares on an exchange-by-exchange basis. The SEC and other securities commissions around the world should report securities fraud committed by investors involving shares of companies on an exchange basis. Investors on an exchange should not only be able to assess the probability that a company or one of its officers will commit fraud, but they should also be able to assess the probability that an unaffiliated investor trading stock listed on the exchange will manipulate the price of that stock. Currently, there is no exchange or securities commission around the world that makes information on fraud involving investors trading corporate stock available to the public and how such statistics differ across different exchanges within the jurisdiction and/or across other jurisdictions. Along with disclosure by securities commissions of fraud caught on an exchange, it should be made clear to investors that more fraud detected does not necessarily imply that there is more fraud committed by investors that trade stock that is listed on that exchange, but rather that securities commissions are actively pursuing wrongdoers on the exchange for the purpose of enhancing exchange quality.

3. Explain and promote market surveillance to investors. Securities commissions should disclose the extent of surveillance and efforts to detect fraud by companies listed on exchanges and investors trading corporate shares of companies on exchanges, and

\footnotetext{
${ }^{18}$ Criticisms of this approach are that the 7\% number is not static over time, and 7\% may well be wide of the mark.
} 
account for differences across exchanges. This disclosure, however, should not be done in a way that would enable would-be market manipulators to adjust their actions to avoid detection. Moreover, securities commissions should not destroy records of possible fraud that was not followed up to fruition, as has been suggested in 2011 interviews with former SEC lawyers (Taibbi, 2011). Investors should be made aware if there are material differences in suspected fraud across different exchanges so that they can appropriately price risk and make better informed investment decisions.

These policy recommendations are of course not meant to be interpreted as being exhaustive or replacing prior policy recommendations on topic. By reporting fraud and steps to alleviate fraud, exchanges can proactively take steps to better inform and protect investors above and beyond the current status quo.

\section{Conclusion}

The SEC should revisit the way it reports cases of fraud within financial markets to investors. There was a time when NASDAQ was considered a relatively risky market, particularly around the bursting of the DotCom bubble, and with the recent introduction of the relatively riskier NASDAQ BX Venture Market which was approved by the Securities and Exchange Commission (SEC) in May 2011, regulators should be more cognizant of the fact that investors should have full information as to the risks associated with investing in different exchanges and take steps to better disclose such risks. Having junior stock markets is not necessarily a bad thing; on the contrary, junior markets can fill a void in terms of providing 
smaller and younger firms with greater opportunities to raise capital and investors a greater opportunity to diversify their portfolios. Companies listed on and investors in junior stock markets however can be better served if there is a reliable source of information pertaining to the relative likelihood of different types of fraud on different exchanges so that investors may make more informed decisions and better carry out their own due diligence.

In this paper we examined how reduced listing standards reporting requirements for companies have worked in the most developed markets in the world, the U.S, the U.K and Canada. We also referred to the markets of Brazil, China and Germany for comparison. We reported data collected for the first time on differences in fraudulent activity in terms of litigated cases of fraud for companies listed on junior versus senior exchanges in these countries. Essentially, our motivation for this collection and analysis of data is that we find it rather surprising thatthere is little or no direct source of evidence on actual litigated cases of fraud that enables an investor to compare the levels of investment risk in different jurisdictions, or even different exchanges within the same jurisdiction.

In the U.S., unless investors carry out the data gathering and analysis that we are carrying out here, they may find it almost impossible to compare actual fraud cases on NYSE versus NASDAQ, or to draw comparison with the PinkSheets. While Canadian investors may refer to annual reports on litigated fraud, there really is no readily available document that enables an investor to make comparisons of litigated fraud between the senior TSX versus the junior TSXV. Similarly in the U.K., there is no readily available basis to compare litigated fraud on the senior LSE with the junior AIM market. This is the first attempt to not only look at 
differences in fraudulent activity in terms of litigated cases of fraud for companies listed in the developed jurisdictions, but more significantly among junior versus senior exchanges.

To examine reported cases of fraud on exchanges in Canada (TSX and TSXV), the U.K. (LSE and AIM), and the U.S. (NYSE, NASDAQ and the PinkSheets), we assembled a unique dataset by recording court documents and news reports over the period January 2005 to June 2011. The data collected highlight differences in frequency of litigated cases of fraud depending on the country as well as the different levels of the exchanges. For example, regression analyses indicated an increase in minimum capitalization requirements by 1-standard deviation is associated with a drop by in the total number of initiated fraud cases by $27.4 \%$. Similarly, a 1standard deviation increase in minimum capitalization is associated with a reduction in the total number of sanctioned cases by $45.8 \%$ relative to the average number of cases in each exchangeyear in the data. We examined other differences in the data depending on the specific type of fraud. The evidence in this report highlights a need for regulators to account for different levels of litigated fraud on different exchanges and to make this information available to average investors who seek to understand risks associated with investing in different products.

While more onerous exchange standards may prove too resource-intensive for some fund-worthy companies to meet, they do nevertheless give market participants a signal of the quality of the exchange and the nature of the companies trading on the exchange. Exchanges are thought of as the first-line system of governance to signal quality in terms of screening out lower-quality, less-mature listings. Higher standards reduce the probability of having poorly 
governed companies seeking funding from stock markets and hence lower the probability of fraud carried out by companies, to the detriment of investors trading in stock.

Lowering disclosure requirements and exchange listing standards undoubtedly affect the ability of an exchange to certify quality to public investors and thereby may have detrimental effects on pricing and liquidity. The data in this report suggest recent changes towards lowering listing standards in the U.S., including but not limited to the NASDAQ BX Venture Exchange, are also likely to be associated with increases in the extent and type of observed fraud. These findings by themselves do not mean that lower listing standards are inappropriate. However, with these findings we are able to determine the extent to which regulations are violated and seek to mitigate the severe and long-lasting damage to companies and investor sentiment by implementing targeted policy reforms.

\section{References}

Becker, G., 1968. “Crime and Punishment: An Economic Approach,” Journal of Political Economy, vol. 76, 169-217.

Blakes, Cassels and Graydon LLP., 2010. “Accessing the Canadian Capital Markets: Legal Considerations for Non-Canadian Mining and Oil and Gas Companies”, July.

Burghof, H.P. and A. Hunger,2003. “Access to Stock Markets for Small and Medium Sized Growth Firms: The Temporary Success and Ultimate Failure of Germany's Neuer Markt”, Working Paper, University of Hohenheim.

Carpentier, C., D.J. Cumming, and J.M. Suret, 2012. "The Value of Capital Market Regulation: IPOs versus Reverse Mergers,” Journal of Empirical Legal Studies, vol. 9, 56-91.

Coffee, J.C., 2005. “A Theory of Corporate Scandals: Why the U.S. and Europe Differ, Oxford Review of Economic Policy, vol. 21, 198-211.

Cumming, D.J. and S. Johan, 2008. “Global Market Surveillance,” American Law and Economics Review vol. 10, 454-506.

Cumming, D.J., S.A. Johan, and D. Li, 2011. "Exchange Trading Rules and Stock Market Liquidity," Journal of Financial Economics, vol. 99(3), 651-671. 
Economist Intelligence Unit, The Economist, available at http://www.eiu.com/index.asp?layout=ib3Article\&article id=827089267\&country id=1480000148\&pubt ypeid $=1132462498 \&$ industry_id $=640001064 \&$ category_id $=\& \mathrm{rf}=0$

Farber, D.B., 2005. “Restoring Trust after Fraud: Does Corporate Governance Matter?” The Accounting Review, vol. 80, 539-561.

Financial Services Authority, 2002. "Review of the Listing Regime", July, available at http://www.fsa.gov.uk/pubs/discussion/dp14.pdf .

Harris, D.A., 2006. "The Impact of Hot Issue Markets and Noise Traders on Stock Exchange Listing Standards,” University of Toronto Law Journal, vol. 56, 223-280.

Hoffman, D., 2011. "Brazil's first Insider Trading Conviction.”, available at http://www.concurringopinions.com/archives/2011/02/brazils-first-insider-trading-conviction.html

Hou, W. and G. Moore, 2010. "Player and Referee Roles Held Jointly: The Effect of State Ownership on China’s Regulatory Enforcement Against Fraud”, Journal of Business Ethics, vol. 95, 317-335.

Jackson, H.E. and M.J. Roe, 2009. "Public and Private Enforcement of Securities Laws: Resource-Based Evidence,” Journal of Financial Economics, vol. 93, 207-238.

Jensen, M.C., 2011. "Putting Integrity into Finance: A Positive Approach (PDF of Keynote Slides)," Harvard NOM Working Paper No. 06-06; Available at SSRN: http://ssrn.com/abstract=876312

Johan, S.A., 2010. “Listing Standards as a Signal of IPO Preparedness and Quality,” International Review of Law and Economics, vol. 30, 128-144.

Karpoff, J., D.S. Lee and G.S. Martin, 2008a. “The Consequences to Managers for Cooking the Books,” Journal of Financial Economics, vol. 88, 193-215.

Karpoff, J., D.S. Lee and G.S. Martin, 2008b. “The Cost to Firms of Cooking the Books” Journal of Financial and Quantitative Analysis, vol. 43, 581-612.

Koyanagi, J. (2008), "Raising Capital on the TSX and AIM", March, available at http://www.tmx.com/en/pdf/RaisingCapitalonTSXandAIM.pdf

La Porta, R., F. Lopez-de-Silanes, A. Shleifer, 2006. “What Works in Securities Laws?” Journal of Finance, vol. 61, 1-32.

La Porta, R., F. Lopez-de-Silanes, A. Shleifer, R. Vishny, 1997. "Legal Determinants of External Finance,” Journal of Finance 52, 1131-1150.

La Porta, R., F. Lopez-de-Silanes, A. Shleifer, R. Vishny, 1998. “Law and Finance,” Journal of Political Economy, vol. 106, 1113-1155.

Macey, J.R. and M. O'Hara, 2002. "The Economics of Stock Exchange Listing Fees and Listing Requirements,” Journal of Financial Intermediation, vol. 11, 297-319.

Mallin, C. 2006. “International Handbook of Corporate Governance”, Cheltenham, U.K.: Edgar Elgar. 
Mallin, C. and K. Ow-Yong, 2010. “The UK Alternative Investment Market - Ethical Dimensions,” Journal of Business Ethics, vol. 95, 223-239.

Peemöller, V.H. and S. Hofmann, 2005. “Bilanzskandale: Delikte und Gegenmaßnahmen”, Berlin: Erich Schmidt Verlag GmbH \& Co.

Petersen, M.A., 2009. "Estimating Standard Errors in Finance Panel Data Sets: Comparing Approaches," Review of Financial Studies 22, 435-480.

Securities and Exchange Commission, 2011. "Microcap Stock: A Guide for Investors”, June, available at http://www.sec.gov/investor/pubs/microcapstock.htm

Securities and Exchange Commission of Brazil, 2011. "The Law that instituted the Comissão de Valores Mobiliários - CVM (Securities and Exchange Commission of Brazil)", available at http://www.cvm.gov.br/ingl/indexing.asp

Taibbi, M., 2011. “Is the SEC Covering Up Wall Street Crimes?”, August, available at http://www.rollingstone.com/politics/news/is-the-sec-covering-up-wall-street-crimes-20110817

Srinivasan, S., 2005. "Consequences of Financial Reporting Failure for Outside Directors: Evidence from Accounting Restatements and Audit Committee Members, Journal of Accounting Research vol. 43, 291334.

Wang, T.Y., A. Winton, and X. Yu, 2012. “Corporate Fraud and Business Conditions: Evidence from IPOs” Journal of Finance, forthcoming. 